\title{
Pars plana vitrectomy with pars plana tube implantation in eyes with intractable glaucoma
}

Suleyman Kaynak, Nalan Fatma Tekin, Ismet Durak, Ayse Tulin Berk, Ali Osman Saatci, Meltem Fatma Soylev

\begin{abstract}
Aims-Intractable glaucoma is glaucoma resistant to medical therapy and conventional surgical procedures. In this study, a planned surgical technique is discussed for controlling the increased intraocular pressure in selected cases with intractable glaucoma.

Methods-Total pars plana vitrectomy with pars plana tube implantation was performed in 17 eyes of 17 cases with intractable glaucoma. Patients with neovascular glaucoma were not included in this study. The mean age of these patients (seven men, 10 women) was 44.6 (SD 22.1) years and mean follow up period was 30.3 (15.5) months (range 4-71). Drainage implants with a disc were used in 16 cases, whereas, a tube with scleral buckle (Schocket surgery) was preferred in one case. An intraocular pressure below or equal to $20 \mathrm{~mm} \mathrm{Hg}$ without any adjunctive medication or with only one type of antiglaucomatous drop was considered as an adequate operative outcome.

Results-16 out of 17 eyes maintained adequate pressure control. Only three out of these 16 eyes required prophylactic antiglaucomatous medications. One patient underwent reoperation for pressure control. The most severe complications observed postoperatively were intravitreal haemorrhage (one case), choroidal detachment (one case), implant failure (one case), total retinal detachment (two cases), and corneal endothelial decompensation (five cases).
\end{abstract}

Conclusion-Pars plana placement of drainage tube following pars plana vitrectomy should be considered as an alternative method for controlling increased intraocular pressures in selected patients with intractable glaucoma.

(Br f Ophthalmol 1998;82:1377-1382)

Ophthalmology, Dokuz

Eylül University,

Izmir, Turkey

S Kaynak

N F Tekin

I Durak

A T Berk

A O Saatci

M F Soylev

Correspondence to: Suleyman Kaynak, MD, Retina Goz Hastaliklari

Arastirma ve Tedavi Merkezi

1388 Sokak, No 16/A, 35220

Alsancak, Izmir, Turkey.

Accepted for publication 24 June 1998
The place of drainage implants in surgical
treatment of resistant glaucoma cases has been criticised since Rollett and Moreau ${ }^{10}$ first used an implant (horse hair) in the treatment of glaucoma 90 years ago. Though numerous studies involving drainage implant surgery did not yield promising results, attempts to create new techniques are still ongoing. ${ }^{11}$ The most preferred surgical technique, in which the drainage tube is placed into anterior chamber, may result in problems related to site of tube implantation. An anterior chamber tube may interact with adjacent tissues which may lead to corneal endothelial decompensation, erosions in iris tissue, haemorrhage, and fibrin formation. Besides, inflammatory and anatomical changes evolving at the interaction site may result in occlusion of the tube. ${ }^{612}{ }^{13}$ Also, tube failure secondary to fibrovascular proliferation around the plate is very common.

The anterior chamber may not be a proper site for tube implantation in selected cases because of numerous serious problems stated above. Hence, we present our 17 cases with pars plana tube insertion and discuss the pros and cons of pars plana tube insertion in cases with intractable glaucoma.

\section{Subjects and methods}

Pars plana tube implantation following total pars plana vitrectomy was performed in 17 eyes of 17 patients with intractable glaucoma. Detailed information about the patients is shown in Table 1 . There were seven men and 10 women, aged 6-68 years (mean 44.5 (SD 22.1) years). Neovascular glaucoma cases, which comprise a specific group of intractable glaucoma with concurrent vitreoretinal disorders, were not included in this study. Thirteen eyes had cataract surgery, five surgery for globe perforation, and four trabeculectomy. Despite being on maximal medical therapy consisting of topical pilocarpine, timolol maleate, dipivefrin, and oral acetazolamide, patients retained an intraocular pressure of $30 \mathrm{~mm} \mathrm{Hg}$ or higher (mean 39.35 (6.75) $\mathrm{mm} \mathrm{Hg}$ with applanation tonometer), associated with glaucomatous optic atrophy. All the patients had elevated intraocular pressures and anatomically disrupted anterior chamber angles with extensive peripheral anterior synechiae secondary to trauma or previous surgeries at the time of presentation. Corneal oedema was present in 15 out of 17 patients before surgery.

Surgeries were performed by one of us (SK) as described below. General anaesthesia was preferred to sustain low intraocular pressures during the operation and to avoid acute hypotony related complications. Valve function of the drainage implant was checked by irrigating through the needle using a sterile balanced salt 
Table 1 Summary of cases

\begin{tabular}{|c|c|c|c|c|c|c|c|c|c|}
\hline $\begin{array}{l}\text { Patient } \\
\text { No, age } \\
\text { (years), } \\
\text { sex }\end{array}$ & Primary diagnosis & Previous operations & Status of lens & $\begin{array}{l}\text { Our surgical } \\
\text { approach }\end{array}$ & $\begin{array}{l}\text { Preop } \\
\text { visual } \\
\text { acuity }\end{array}$ & $\begin{array}{l}\text { Postop } \\
\text { visual } \\
\text { acuity }\end{array}$ & $\begin{array}{l}\text { Preop } \\
\text { IOP } \\
(\mathrm{mm} \\
\mathrm{Hg})\end{array}$ & $\begin{array}{l}\text { Postop } \\
\text { IOP } \\
\text { (mm } \\
\mathrm{Hg})\end{array}$ & $\begin{array}{l}\text { Follow up } \\
\text { (months) }\end{array}$ \\
\hline $1,35, M$ & Perforation+cataract+glaucoma & $\begin{array}{l}\text { Repair of perforation }+ \text { cat } \\
\text { ext }+\mathrm{PK}+\mathrm{Trb}\end{array}$ & Aphakic & (1) PPV-T 2) PK & LP & $20 / 80$ & 40 & 16 & 71 \\
\hline $2,55, M$ & Cataract & Cataract extraction & Aphakic & (1) PPV-T 2) PK & $\mathrm{CF}$ & $20 / 400$ & 38 & 18 & 42 \\
\hline $3,29, \mathrm{~F}$ & Congenital cataract & Cataract extraction & Aphakic & (1) PPV-T & LP & $20 / 400$ & 32 & 15 & 41 \\
\hline $4,68, \mathrm{~F}$ & Cataract & Cataract extraction & Aphakic & (1) PPV-T & LP & $20 / 400$ & 38 & 14 & 40 \\
\hline $5,55, M$ & Cataract & Cataract ext+PK & Aphakic & $\begin{array}{l}\text { (1) PPV-T (2) } \\
\text { Silicone oil surgery }\end{array}$ & LP & LP & 42 & 15 & 40 \\
\hline $6,70, \mathrm{~F}$ & Cataract+glaucoma & Cataract ext+Trb & Aphakic & (1) PPV-T & LP & $20 / 200$ & 40 & 18 & 38 \\
\hline $7,32, \mathrm{~F}$ & Perforation & Repair of perforation & Aphakic & $\begin{array}{l}\text { (1) PPV-T+PK (2) } \\
\text { PK }\end{array}$ & LP & $20 / 200$ & 32 & 14 & 36 \\
\hline $8,9, M$ & Angle recession glaucoma & - & Phakic & (1) PPV-L-T & $\mathrm{CF}$ & LP & 35 & 12 & 32 \\
\hline $9,12, \mathrm{~F}$ & Perforation & Repair of perforation & Aphakic & (1) PPV-T & $\mathrm{CF}$ & $20 / 400$ & 32 & 12 & 30 \\
\hline $10,6, \mathrm{~F}$ & Perforation & Repair of perforation & Aphakic & (1) PPV-T (2) PK & $\mathrm{CF}$ & LP & 35 & 10 & 28 \\
\hline $11,61, \mathrm{~F}$ & Cataract & Cataract extraction & Aphakic & (1) PPV-T (2) PK & LP & LP & 55 & 35 & 26 \\
\hline $12,68, \mathrm{~F}$ & Cataract & Cataract extraction & Pseudophakic & (1) PPV-T & LP & $20 / 50$ & 50 & 16 & 24 \\
\hline $13,64, \mathrm{~F}$ & Cataract & Cataract extraction & Pseudophakic & (1) PPV-T & LP & $20 / 80$ & 35 & 18 & 20 \\
\hline $14,60, \mathrm{~F}$ & Cataract+glaucoma & Cataract ext+Trb & Aphakic & (1) PPV-T & $\mathrm{CF}$ & $20 / 100$ & 42 & 16 & 16 \\
\hline $15,65, \mathrm{M}$ & Cataract+glaucoma & Cataract ext+Trb & Aphakic & (1) PPV-T & $\mathrm{CF}$ & $20 / 80$ & 35 & 14 & 15 \\
\hline $16,33, M$ & Perforation+cataract & $\begin{array}{l}\text { Repair of perforation+ } \\
\text { cataract extraction }\end{array}$ & Aphakic & (1) PPV-T & LP & $\mathrm{LP}$ & 50 & 12 & 12 \\
\hline $17,35, M$ & Congenital cataract & Cataract extraction & Aphakic & (1) PPV-T & $\mathrm{CF}$ & $20 / 400$ & 38 & 20 & 4 \\
\hline
\end{tabular}

$\mathrm{PK}=$ partial penetrating keratoplasty; $\mathrm{Trb}=$ trabeculectomy; PPV-T = pars plana vitrectomy and tube implantation; PPV-L-T = pars plana vitrectomy, lensectomy, and tube implantation; $\mathrm{LP}=$ light perception; $\mathrm{CF}=$ counting fingers; $\mathrm{IOP}=$ intraocular pressure.

solution and the tubing was trimmed to extend into vitreous cavity for $5-6 \mathrm{~mm}$ before insertion. Following 360 degree peritomy, 4.0 silk traction sutures were placed beneath the superior and lateral rectii. Conjunctiva and Tenon's capsule in the superotemporal area were carefully dissected. The plate was secured to sclera superotemporally with 5.0 Dacron, the edges of the plate being under the muscles. An infusion cannula was inserted into the vitreous cavity by inferotemporal pars plana sclerotomy. The corneal epithelium was scraped off to provide adequate visualisation whenever necessary.

Following three port total vitrectomy, the drainage tube was introduced through the superotemporal sclerotomy and advanced 5 $\mathrm{mm}$ into the vitreous cavity. Dura patch (Tutoplast Dura Biodynamics International No 68001) was used to cover the tube and anchored to sclera with 5.0 Dacron.

Drainage implants with a disc (Hood Laboratories catalogue no EY-6003, FCI S-4 2000, Staar surgical long tube glaucoma implantMolteno style) were used in 16 cases, whereas a drainage implant with scleral buckle, consistent with Schocket surgery (Hood Laboratories catalogue No EY-6002) was preferred in one case (case 7).

Three selected cases are described in detail.

CASE 1

A 35 year old man had a history of bilateral corneal perforation secondary to a car accident 7 years earlier. The right eye had been surgically treated for corneal perforation, whereas the left eye had been enucleated. During reparation, a corneal incision of $4 \mathrm{~mm}$ extending to limbus, and hyphaema in the anterior chamber were noted in the right eye. Early postoperatively, the cornea was clear, the anterior chamber was deep, and the lens was clear. Vision was improved to 20/100. The funduscopic examination was unremarkable. Within a year, he developed severe corneal opacification and cataract in the right eye, which was managed with a combined partial penetrating keratoplasty, cataract extraction, and IOL implantation surgery. However, the intraocular lens was explanted in a few months because of intractable secondary glaucoma and a second penetrating keratoplasty was performed.

During the follow up, diffuse peripheric anterior synechiae and high intraocular pressures (up to $80 \mathrm{~mm} \mathrm{Hg}$ ) unresponsive to medical treatment were noted in the right eye. One year later, after two consecutive trabeculectomies elsewhere, he returned to our clinic for further evaluation. Slit lamp examination revealed a grossly oedematous and thickened graft and an apparently deep anterior chamber, but details of the anterior chamber were not visible. The visual acuity was at light perception level. Funduscopic examination revealed nearly total optic atrophy. Intraocular pressure measurements ranged between 40 and $50 \mathrm{~mm}$ $\mathrm{Hg}$. A drainage implant surgery was considered necessary. A "valved Krupin tube" was introduced through superotemporal sclerotomy at pars plana following complete pars plana vitrectomy. The IOP responded well, dropping to $10 \mathrm{~mm} \mathrm{Hg}$ postoperatively and eventually stabilising at $15-16 \mathrm{~mm} \mathrm{Hg}$ in the following months. However, the corneal oedema did not resolve, eventually requiring the third penetrating keratoplasty 2 months later. IOP remained stable for 71 months since the last operation (penetrating keratoplasty). Currently, the patient's visual acuity remains at $20 / 80$ with a very narrow visual field. He continues to use timolol maleate twice daily prophylactically.

\section{CASE 3}

A 29 year old woman had a history of bilateral cataract extraction in childhood for congenital cataract. Horizontal nystagmus and a right phthisical globe were noted at the time of presentation. The visual acuity was light perception in the left eye. Slit lamp examination of the left eye revealed an oedematous cornea and 
cicatricial angle closure associated with aphakia. The intraocular pressure was $32 \mathrm{~mm} \mathrm{Hg}$ in the left eye, despite being on maximal medical treatment. The funduscopic examination of the left eye showed glaucomatous optic atrophy. Surgical treatment was deemed necessary. After a complete pars plana vitrectomy, a valved Krupin tube was introduced into the vitreous cavity through superotemporal sclerotomy at the pars plana. The pressure gradually decreased and stabilised at $14-15 \mathrm{~mm} \mathrm{Hg}$ and the corneal oedema completely resolved by the first postoperative month. The intraocular pressure was maintained within normal limits and the visual acuity stayed at 20/400 throughout the 41 months of follow up.

CASE 7

A 32 year old woman had been operated in her childhood for corneal perforation and cataract extraction in the left eye. At the time of presentation, her visual acuity was light perception in the left eye. Slit lamp examination of the left eye disclosed an oedematous and irregularly thickened cornea, and 360 degree peripheral anterior synechiae. The intraocular pressure was $32 \mathrm{~mm} \mathrm{Hg}$ in the left eye despite treatment for glaucoma. Ultrasonographic examination of the left eye revealed an axial length of $27 \mathrm{~mm}$ and excavation in the optic nerve head, but an otherwise normal posterior segment: $10^{\circ}$ left exotropia was noted by cover-uncover test. She was offered drainage implant surgery for controlling the increased intraocular pressure. The surgical treatment was performed in two steps. Firstly, a valved Krupin tube with scleral buckle (Hood Laboratories catalogue No EY-6002) was implanted and secured to the sclera in four quadrants, leaving the tips untied. Encircling band was used as the patient was highly myopic. A second operation was performed 3 weeks later. Firstly, a Flieringa ring was secured and an infusion cannula was inserted into vitreous cavity through inferotemporal pars plana sclerotomy. Then, the cornea was dissected with a $7 \mathrm{~mm}$ trephine and was replaced with an Eckard prosthesis (DORC-1285-1). Following total pars plana vitrectomy, the tube was introduced and advanced $5 \mathrm{~mm}$ into the vitreous cavity. The tube was anchored to the sclera with 5.0 Dacron and covered with a dura patch. Then the Eckard prosthesis was removed and replaced with a previously prepared $7.5 \mathrm{~mm}$ graft. Finally, after tightening the encircling band, the Flieringa ring and the infusion cannula were removed.

Profound depression of the band secondary to marked hypotony, choroidal detachment, and trace vitreous haemorrhage was noted by the first postoperative week. These hypotony related complications resolved spontaneously in 2 weeks as the intraocular pressure stabilised at $13-14 \mathrm{~mm} \mathrm{Hg}$, and the vision improved to 20/200. However, she developed diffuse corneal haze secondary to endothelial insufficiency despite stabilised intraocular pressures and she underwent a second penetrating keratoplasty at the end of 36th follow up month. Currently, the graft is still clear, the

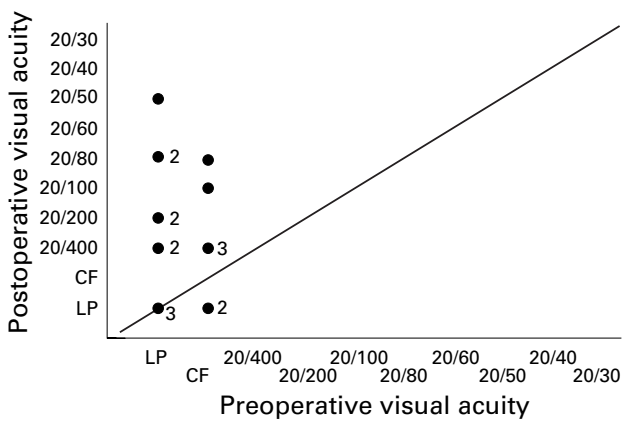

Figure 1 Preoperative and postoperative visual acuities.

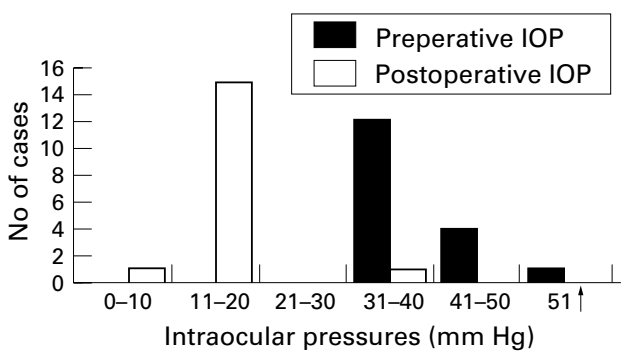

Figure 2 Preoperative and postoperative intraocular pressures.

visual acuity is $20 / 200$, and the intraocular pressure remains within normal limits.

\section{Results}

The mean follow up period following the surgery was 30.3 (SD 15.5) months (range 4-71 months). Preoperative and postoperative visual acuities can be seen in Figure 1.The intraocular pressures were stabilised by the third or fourth week postoperatively, except one case (case 11). Antiglaucomatous medications were not needed in 13 out of 17 cases following the operation. Three eyes (cases 1, 7, and 17) required prophylactic medications (topical timolol maleate) as they were difficult to follow regularly for social reasons. One case (case 11) had high intraocular pressures postoperatively secondary to fibrovascular proliferation around the plate and did not respond to reoperation. Sixteen patients maintained normal intraocular pressures throughout the follow up, though two had rhegmatogenous retinal detachments, with retinal tears located at other than sclerotomy sites (cases 5 and 16). Preoperative and postoperative intraocular pressures are seen in Figure 2.

Four of 15 cases (cases 1, 2, 10, and 11) required penetrating keratoplasty following the drainage implant surgery; whereas, one case (case 7) had corneal grafting at the same session. The intraocular pressures were maintained and supplemented with a Flieringa ring in conjunction with continuous pars plana infusion during corneal grafting in all these patients. One of these five grafted patients (case 7) developed corneal haze secondary to corneal endothelial insufficiency, which was attributed to postoperative hypotony. Two cases (cases 1 and 5) with history of previous keratoplasty developed aphakic glaucoma following their primary surgeries. Case 1 was discussed in detail. 
Table 2 Postoperative complications following drainage implant surgery

\begin{tabular}{ll}
\hline Complications & No of patients (\%) (case numbers) \\
\hline Hypotony & $2(12)$ (cases 7 and 12) \\
Intravitreal haemorrhage & $1(6)$ (case 12) \\
Serous choroidal detachment & $1(6)$ (case 7) \\
Rhegmatogenous retinal detachment & $2(12)$ (cases 5 and 16) \\
Corneal endothelial decompensation & $5(30)$ (cases $1,2,7,10$, and 11) \\
Implant failure & $1(6)$ (case 11) \\
\hline
\end{tabular}

Case 5 had a history of previous keratoplasty because of bullous keratopathy, which resulted in elevated intraocular pressure secondary to obliteration of the iridocorneal angle. Both medical treatment and filtration surgery were attempted and failed. Eventually, pars plana tube implantation following complete pars plana vitrectomy was performed, providing adequate pressure control for 2 months. Meanwhile, the patient developed total rhegmatogenous retinal detachment in the same eye, which was managed with intravitreal silicone oil surgery. A few weeks later, the silicone oil diffused into the anterior chamber resulting in high intraocular pressure which was resistant to medical treatment. Following silicone oil removal 1.5 months later, retinal detachment recurred, but the patient refused reoperation. Currently, the intraocular pressure is stabilised, the graft is clear, but the retina is totally detached. In summary, four out of these five grafted patients (cases $1,2,10$, and 11) still have clear grafts, with no evidence of graft rejection.

Following the drainage implant surgery, one patient (case 7) developed serous choroidal detachment which lasted for 2 weeks, and another patient (case 12) developed intravitreal haemorrhage most likely secondary to hypotony. Both complications resolved spontaneously within 2 weeks. Two cases (cases 5,16 ) developed total rhegmatogenous retinal detachment, with retinal tears located at other than sclerotomy sites, a few months after drainage implant surgery. One (case 5) underwent silicone oil surgery while the other refused further surgery.

Detailed information about postoperative complications is shown in Table 2.

\section{Discussion}

Intractable glaucoma is resistant to medical treatment and/or conventional surgical approaches and alternative surgical techniques should be sought. One alternative is trabeculectomy with adjunctive antifibrosis agents like mitomycin C or 5-fluorouracil, which may improve success rates up to $89 \% \cdot{ }^{14-16}$ Different types of cyclodestructive procedures can also be performed. Cyclocryotherapy carries a high risk of phthisis, whereas laser induced cyclodestructive procedures are relatively safer. However, cyclodestructive procedures can cause irreversible damage to intraocular tissues or fail to maintain adequate pressure control. ${ }^{17-22}$

Drainage implant surgery, which creates an alternative pathway for aqueous outflow without destroying the ciliary body seems to be a promising alternative in cases with resistant glaucoma. This procedure aims to provide a continuous but sufficient drainage through an artificial pathway. Though this procedure was first proposed in 1920s, an appropriate tool could only be designed in 1960s. ${ }^{11}{ }^{23}$

The first designed translimbal setons connected the anterior chamber to subconjunctival space. Most of these implants failed secondary to subconjunctival fibrosis and eventual scarring of the bleb. ${ }^{24}$ With time, setons providing a translimbal-equatorial shunt that would promote formation of a fuctional bleb were designed. ${ }^{25}$ In various studies, complications such as shallow anterior chamber, hyphaema, obstruction of the tube, pupillary blockage, cataract, corneal endothelial insuficiency, choroidal detachment, and choroidal haemorrhage developed in up to $90 \%$ of the cases, requiring reoperation in one third of the patients. ${ }^{23} 26$ Cyclodialysis in conjunction with anterior chamber tube implantation, in which the success rates approached $60 \%$, was proposed as an alternative treatment. ${ }^{28}$ One of the implants used in shunt surgery was ACTSEB (anterior chamber tube shunt to an encircling band). The success rate of the drainage implant surgery with this material was reported to be as high as $70 \%$; however, $54 \%$ of patients required reoperation. ${ }^{29}{ }^{30}$ Results of studies utilising limbal and translimbal-equatorial tubes were mostly unsatisfactory, necessitating alternative surgical techniques. Pars plana vitrectomy combined with an anterior chamber tube has been tried. Unfortunately, the tube was frequently plugged with vitreous. Therefore, new filtering strategies utilising the pars plana approach were described..$^{3132}$

Recently, pars plana vitrectomy with pars plana tube implantation was performed in selected cases with glaucoma associated with shallow and/or an extensively closed anterior chamber angle, aphakia or pseudophakia, neovascular glaucoma, and glaucoma with concurrent vitreoretinal disorders. ${ }^{73} 34$ In this technique, the risks of tube tissue interaction and outflow obstruction were minimised. In this study, we performed pars plana tube implantation in 17 cases with intractable glaucoma, who were not considered as favourable candidates for any other procedures. The conventional anterior segment placement was not preferred in these cases in order to avoid the risk of corneal touch due to extensive peripheric anterior synechiae. Studies involving pars plana tube implantation following pars plana vitrectomy are limited (Table 3). Gandham et $a l^{7}$ performed total pars plana vitrectomy and pars plana tube implantation in eight eyes in a series of 20 with refractory glaucoma and tube implantation into anterior chamber in the remaining 12 eyes. He reported favourable results with a mean postoperative intraocular pressure below $22 \mathrm{~mm} \mathrm{Hg}$ (with or without medication) in 15 eyes ( $75 \%$ ), unchanged or improved visual acuities in 13 eyes $(65 \%)$, and no outflow obstruction related complications in the follow up (4.2-28 months). Varma et al ${ }^{33}$ performed pars plana vitrectomy and pars plana tube implantation in 13 eyes with intractable glaucoma associated with aphakia or pseudophakia and shallow anterior chamber or 
Table 3 Studies on pars plana vitrectomy and tube implantation

\begin{tabular}{|c|c|c|c|c|c|c|}
\hline Ref (study year) & No of eyes & Diagnosis of patients & Type of surgery & Type of implant & $\begin{array}{l}\text { Glaucoma } \\
\text { control (no } \\
\text { of eyes) }\end{array}$ & $\begin{array}{l}\text { Mean follow up } \\
\text { (months) }\end{array}$ \\
\hline $\begin{array}{l}\text { Granham et al } \\
\text { (1993) }\end{array}$ & 20 & $\begin{array}{l}\text { Glaucoma associated with vitreoretinal } \\
\text { disorders (neovascular glaucoma, } \\
\text { aphakic or pseudophakic glaucoma) }\end{array}$ & $\begin{array}{l}\text { Standard vitrectomy } \\
\text { surgery+glaucoma seton valve surgery } \\
\text { with pars plana tube insertion ( } 8 \\
\text { cases) or tube insertion into anterior } \\
\text { chamber ( } 12 \text { cases) }\end{array}$ & $\begin{array}{l}\text { Molteno or } \\
\text { Schocket implant }\end{array}$ & 15 & $4.2-28$ \\
\hline $\begin{array}{l}\text { Smiddy et al } \\
\quad(1994)\end{array}$ & 10 & $\begin{array}{l}\text { Glaucoma associated with disrupted } \\
\text { anterior chamber (congenital, angle } \\
\text { recession, phacomorphic, secondary } \\
\text { angle closure, chronic open angle } \\
\text { glaucoma) }\end{array}$ & $\begin{array}{l}\text { Standard vitrectomy surgery } \\
\text { + glaucoma seton valve surgery with } \\
\text { pars plana tube insertion+ligation of } \\
\text { tube }\end{array}$ & $\begin{array}{l}\text { Molteno or } \\
\text { Baerveldt implant }\end{array}$ & 9 & $3-24$ \\
\hline $\begin{array}{l}\text { Varma et al } \\
(1995)\end{array}$ & 13 & $\begin{array}{l}\text { Glaucoma associated with shallow } \\
\text { anterior chamber or vitreus prolapsus } \\
\text { into anterior chamber and aphakic or } \\
\text { pseudophakic glaucoma }\end{array}$ & $\begin{array}{l}\text { Standard vitrectomy surgery } \\
\text { + glaucoma seton valve surgery with } \\
\text { pars plana tube insertion+ligation of } \\
\text { tube }\end{array}$ & Baerveldt implant & 11 & $12-28$ \\
\hline $\begin{array}{l}\text { Present study } \\
\text { (1998) }\end{array}$ & 17 & $\begin{array}{l}\text { Glaucoma associated with disrupted } \\
\text { anterior chamber (angle recession, } \\
\text { secondary angle closure) and aphakic or } \\
\text { pseudophakic glaucoma }\end{array}$ & $\begin{array}{l}\text { Standard vitrectomy surgery } \\
\text { + glaucoma seton valve surgery with } \\
\text { pars plana tube insertion }\end{array}$ & $\begin{array}{l}\text { Molteno or } \\
\text { Schocket implant }\end{array}$ & 16 & $4-71$ \\
\hline
\end{tabular}

vitreous prolapsus into anterior chamber. In their study, 11 eyes $(85 \%)$ maintained stable intraocular pressures with only six eyes requiring additive pressure lowering medications postoperatively. The visual acuities of nine eyes either remained the same or improved in the follow up (12-28 months). Smiddy and colleagues $^{34}$ reported 10 patients treated with pars plana tube implantation following pars plana vitrectomy. The mean postoperative intraocular pressure was equal to or below 15 $\mathrm{mm} \mathrm{Hg}$ on no pressure lowering medications in nine eyes, and the visual acuity remained the same or improved in seven eyes in the follow up (3-24 months). In our series, all the preoperative intraocular pressures were above $30 \mathrm{~mm}$ $\mathrm{Hg}$, and all the postoperative intraocular pressures were below or equal to $20 \mathrm{~mm} \mathrm{Hg}$, with pressure lowering medications in two cases, with one exception (case 11) who was also kept on medications. The visual acuities of most of our patients either remained the same (three patients) or slightly improved (12 patients), underlining the efficiency and safety of the surgery. However, media opacities (corneal oedema, cataract) that were frequent in our series before surgery may have been attributed to the relatively high proportion of visual improvement.

In the study of Varma et $a l^{33}$ two eyes experienced restriction in ocular motility following the surgery. Although we did not observe such a complication, eight of our patients had only one eye. Varma et al did not observe any hypotony related complications during the early postoperative period, which may be explained by their ligature technique. Smiddy et al observed choroidal effusion in two cases 1 month following the surgery, which may be due to acute hypotony related to resorption of the suture obstructing the tube. Such complications were evident in our study despite our preference for valved implants, which are believed to reduce postoperative overdrainage..$^{35} 36$

In our study, five patients (cases $1,2,7,10$, and 11) developed corneal haze requiring penetrating keratoplasty. We believe that corneal endothelial decompensation seen in these patients was most likely due to earlier surgeries or trauma and prolonged ocular hypertension as this procedure is relatively safe in terms of corneal endothelial touch.

In light of our study, we believe that total pars plana vitrectomy with pars plana tube insertion is an alternative approach in selected cases with refractory glaucoma associated with extensive peripheric anterior synechiae. However, caution should be exercised in patient selection as this procedure is not devoid of serious complications. Special attention should be focused on cleaning of vitreous base in order to prevent vitreous incarceration and tube dysfunction.

This paper was presented in part at the 27th International Congress of Ophthalmology, 1994 Toronto, Canada.

1 Grant WM, Walton DS. Progressive changes in the angle in congenital aniridia, with development of glaucoma. $A m \mathcal{F}$ Ophthalmol 1974;78:842-7.

2 Wiggins RE, Tomey KF. The results of glaucoma surgery in aniridia. Arch Ophthalmol 1992;110:503-5.

3 Bellows AR, Johnstone MA. Surgical management of chronic glaucoma in aphakia. Ophthalmology 1983;90:80713.

4 Heuer DK, Gressel MG, Parrish RK, et al. Trabeculectomy in aphakic eyes. Ophthalmology 1984;91:1045-51.

5 Netland PA, Walton DS. Glaucoma drainage implants in pediatric patients. Ophthalmic Surg 1993;24:723-9.

6 Rose GE, Lavin MJ, Hitchings RA. Silicone tubes in glaucoma surgery: the effect of technical modifications on early postoperative intraocular pressures and complications. Eye 1989;3:553-61.

7 Gandham SB, Costa VP, Katz LJ, et al. Aqueous tube-shunt mplantation and pars plana vitrectomy in eyes with refractory glaucoma. Am f Ophthalmol 1993;116:189-95.

8 Costa VP, Katz LJ, Cohen EJ, et al. Glaucoma associated with epithelial downgrowth controlled with Molteno tube shunts. Ophthalmic Surg 1992;23:797-800.

9 Sherwood MB, Smith MF, Driebe WT Jr, et al. Drainage tube implants in the treatment of glaucoma following keratoplasty. Ophthalmic Surg 1993;24:185-9.

10 Rollett $M$, Moreau $M$. Le drainage au crin de la chambre anterieure contre l'hypertonie et la douleur. Rev Gen anterieure contre l'hypertoni

11 Molteno ACB. Use of Molteno implants to treat secondary glaucoma. In: Carins JE, ed. Glaucoma. London: Grune glaucoma. In: Carins JE, ed. Glaucoma.
and Stratton, 1986;Chapter 10: 211-38.

12 Melamed S, Cahane M, Gutman I, et al. Postoperative complications after Molteno implant surgery. Am $\mathcal{F}$ Ophthalmol 991;111:319-22.

13 McDermott ML, Swendris RP, Shin DH, et al. Corneal endothelial cell counts after Molteno implantation. Am $\mathcal{F}$ Ophthalmol 1993;115:93-6.

14 Heuer DK, Parrish RK, Gressel MG. 5-Fluorouracil and glaucoma filtering surgery: III. Intermediate follow-up of a pilot study. Ophthalmology 1986;93:1537-46.

15 Skuta GL, Beeson CC, Higginbotham EJ, et al. Intraoperative mitomycin versus postoperative 5-fluorouracil in high risk glaucoma filtering surgery. Ophthalmology 1992;99: 438-44.

16 Kitazawa Y, Kawase K, Matsushita H, et al. Trabeculectomy with mitomycin. A comparative study with fluorouracil. with mitomycin. A comparative stuc

17 Wesley RE, Kielar RRA. Cyclocryotherapy and treatment of glaucoma. Glaucoma 1980;3:533-8. 
18 Shields MB. Cyclodestructive procedures.In: Shields $M B$ ed. Textbook of glaucoma. 2 nd ed. Baltimore: Williams and ed. Textbook of glaucoma.
Wilkins, 1987:500-10.

19 Binder PS, Abel R, Kaufmann HE. Cyclotherapy for glaucoma after penetrating keratoplasty. Am F Ophthalmol 1975;79:489-92.

20 Levy NS, Bonney RC. Transscleral YAG cyclocoagulation of the ciliary body for persistantly high intraocular pressure following keratoplasty. Cornea 1989;8:178-81.

21 Patel A, Thompson JT, Michels RG, et al. Endolaser treatment of the ciliary body or uncontrolled glaucoma. Ophthalmology 1986;93:825-30.

22 Gaasterland DE, Poolack IP. Initial experience with a new method for laser transscleral cyclophotocoagulation for ciliary ablation in severe glaucoma. Trans Am Ophthalmol Soc 1992;90:225-46.

23 Fellman RI, Lynn JR. Glaucoma series: modern-day ocular drainage implants. In: Starita RJ, ed. Clinical signs in drainage implants. In: Starita RJ, ed.
ophthalmology. St Louis: Mosby, 1989:11.

24 Miller MH, Grierson I, Unger WI, et al. Wound healing in an animal model of glaucoma fistulizing surgery in the raban animal model of glaucoma fistulizing

25 Molteno ACB. New implant for drainage in glaucoma. Clinical trial. Br f Ophthalmol 1969;53:606-1

26 Krupin T, Kaufman P, Mandel A. Filtering valve implant surgery for eyes with neovascular glaucoma. Am f Ophthalmol 1980;89:338-43.

27 Krupin T, Spector SC. Setons in glaucoma surgery. In:
Ritch R, Shields MB, Krupin T, eds. The glaucomas. St Louis: Mosby,1989; Chapter 19:741-8.
28 Sherwood MB, Joseph NH, Hitchings RA. Surgery for refractory glaucoma: results and complications with a modified Schocket technique. Arch Ophthalmol 1987;105: $562-9$.

29 Sarkies NJC, Hitchings RA. Silicone tube and gutter in dvanced glaucoma. Trans Ophthalmol Soc UK 1985;104: 133-6.

30 Hitchings RA, Lattimer J. How to manage the unresponsive patient. Eye 1987;1:55-61.

31 Lloyd MA, Heuer DK, Baerveldt G, et al. Combined Molteno implantation in pars plana vitrectomy for neovascular glaucoma. Ophthalmology 1991;98:1401-5.

32 Sinclair SH, Aaberg TM, Meredith TA. Pars plana filtering procedure combined with lensectomy and vitrectomy for neovascular glaucoma. Am f Ophthalmol 1982;93:185-91.

33 Varma R, Heuer DK, Lundy DC, et al. Pars plana Baerveldt tube insertion with vitrectomy in glaucomas associated with pseudophakia and aphakia. Am f Ophthalmol 1995; 119:401-7.

34 Smiddy WE, Rubsamen PE, Grajewski A. Vitrectomy for pars plana placement of a glaucoma seton. Ophthalmic Surg 1994;25:532-5.

35 Joseph NH, Sherwood MB, Trantas G, et al. A one-piece drainage system for glaucoma surgery. Trans Ophthalmol drainage system for glaucom
Soc $U K$ 1986;105:657-64.

36 Hitchings RA, Joseph NH, Sherwood MB, et al. Use of onepiece valved tube and variable surface area explant for glaucoma drainage surgery. Ophthalmology 1987;94:107984. 